\title{
The Empirical Study and Construction of Performance Evaluation Model of the Financial Input in Science and Technology
}

\author{
Yin Fan \\ Environmental Management College of China \\ Qinhuangdao, China \\ yinfan1015@163.com
}

\begin{abstract}
This article innovatively puts forward with the standard to evaluate the performance of the financial input to science and technology and constructs the DEA/EFA performance evaluation model. Based on the date of 2012 and 2013, this article demonstrates how to use the model and makes a concrete analysis of the measures to improve the performance of the financial input to science and technology of Hebei Province in China, thus offering references to the government.
\end{abstract}

Keywords-Financial Input to Science and Technology, Performance Evaluation, DEA/EFA, Performance Optimum

\section{INTRODUCTION}

As increasing the reliability of the evaluation conclusion, this paper further improves the scientificity of analyzing related restrict factors, thus provides forceful theoretical foundation for governmental scientific decision, increasing the scientificity of the usage of the financial funds and enhancing governmental managerial capacity in science and technology.

\section{MODEL STRUCTURE}

\section{A. Idea on constructing the model}

The conception of performance evaluation originates form Enterprise Management and there is no agreement on its meaning. In this situation, it has increased the importance of having a clear-cut criterion to evaluate the performance of the financial input to science and technology. This paper centers about the criterion. It is believed that performance, which is a concept with so rich connotation that it cannot be calculated by precise figures, but can determine relative discrepancy between the evaluated target and other samples thus judging its performance only by comparing and judging overall samples. The discrepancy here includes two main areas at least: funds use efficiency and the technology gap brought by financial input to science and technology, which can be measured by different evaluating strategies and comprehensively judged the performance according to the results. As the outcomes have a relatively strong dependency on the evaluation methods, this paper considers using Data Envelopment Analysis and Exploratory Factor Analysis.

Data Envelopment Analysis (DEA for short) is first proposed by famous American operational research experts A.Charnes, W.Cooper and the others in 1978[1].
Exploratory Factor Analysis (EFA for short) and Confirmatory Factor Analysis (CFA for short) are the two forms of Factor Analysis and they are one of the statistical analysis methods of descent in multivariate analysis. For details of the relations and differences between them see references [2]. This paper uses EFA and its fundamental principles and calculation procedure can be found in reference [3].

\section{B. DEA/EFA performance evaluation model}

DEA and EFA can be used independently in performance evaluation, but both have their defect. The advantage of DEA is that it doesn't have to give the weights standing for decision-maker' preference and provide the input-output functional relation. However, the conclusion only indicates relative effectiveness. When the effectiveness of several unit objectives equals to 1 , it is difficult to arrange their effectiveness. The combined values of EFA can reflect the maximal combined differences of unit objectives, but the changing symbol of the evaluation matrix makes the meaning of the function obscure[4], which cannot reflect the effectiveness of inputoutput and provide methods to improve the unit objectives according to projection principle. Therefore, this paper combines the two methods together and construct DEA/EFA evaluation model as shown in Fig. 1.

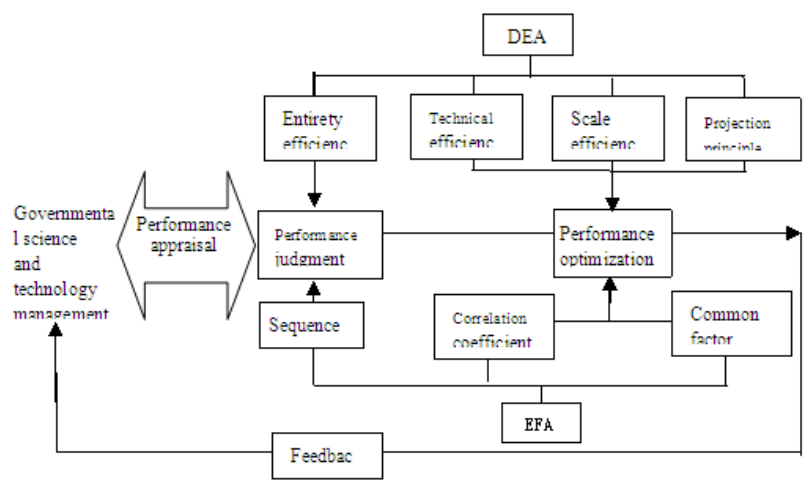

Fig 1. DEA/EFA model of performance evaluation of financial input to science and technology

This paper holds that the criteria for evaluation depend on the influence of the service efficiency of the financial input to science and technology and the scientific and technological strength brought by the input. In the concrete evaluating process, the service efficiency of the financial input to science and technology can be worked out by the 
C2R model of DEA while the synthetical differences of the scientific and technological strength by EFA, and the performance of the unit objectives depend on the two composite scores[5]. Take the score of $\mathrm{C} 2 \mathrm{R}$ model as horizontal ordinate and that of EFA as vertical ordinate; a two-dimensional graph can be obtained with Values of horizontal ordinate range from 0 to 1 . Its performance is assumed as excellent. The $\mathrm{C} 2 \mathrm{R}$ values of the unit objectives in region $\mathrm{B}$ are higher while the EFA values are low, which means high finance service efficiency but low development level of science and technology. Situation of the region $\mathrm{C}$ is the opposite and we assume their performance as average. The $\mathrm{C} 2 \mathrm{R}$ and EFA values of the unit objectives in region $\mathrm{D}$ are low, which means low finance service efficiency and low development level of science and technology and we assume its performance as poor.

According to the DEA/EFA model, the method to improve the efficiency of unit objectives can be found which mainly touches on analyzing the overall efficiency, technical efficiency and scale efficiency. The way can be found to strengthen scientific and technological capabilities of unit objectives, thus make its performance improving track fall in the area A of Fig. 2.

\begin{tabular}{|c|c|c}
\hline $\begin{array}{c}\text { C } \\
\text { High level-low } \\
\text { efficiency }\end{array}$ & $\begin{array}{c}\text { A } \\
\text { High level-high } \\
\text { efficiency }\end{array}$ & High \\
\hline $\begin{array}{c}\text { Low level-low } \\
\text { efficiency }\end{array}$ & $\begin{array}{c}\text { B } \\
\text { Low level-high } \\
\text { efficiency }\end{array}$ & \multirow{A}{*}{ Low } \\
\hline Low & $\mathrm{C}^{2} \mathrm{R}$ & High
\end{tabular}

FIG 2. CHART OF THE COMPOSITE PERFORMANCE JUDGMENT

\section{EMPIRICAL STUDIES}

Taking 28 regions of the China as samples, this paper makes a concrete analysis of the performance optimization of the financial input to science and technology of Hebei Province, and gives a detailed description of the DEA/EFA model. The performance evaluation index system is selected for science and technology, as it shown in Table 1.

TABLE I INDEX SYSTEM OF THE PERFORMANCE EVALUATION OF FINANCIAL INPUT TO SCIENCE AND TECHNOLOGY

\begin{tabular}{|c|c|c|}
\hline Type & Primary index & Secondary index \\
\hline Input & $\begin{array}{l}\text { Financial input to } \\
\text { science and } \\
\text { technology }\end{array}$ & $\begin{array}{l}\text { Proportion of finance input to science and technology } \\
\text { in public finance expenditure (X1) }\end{array}$ \\
\hline \multirow{6}{*}{ Output } & Direct output & $\begin{array}{l}\text { Amount of papers on science and technology (X2) } \\
\text { Amount of patent application and authorization (X3) }\end{array}$ \\
\hline & \multirow{3}{*}{ Economic benefit } & Transaction value on technology market (X4) \\
\hline & & $\begin{array}{c}\text { Proportion of added value in high-tech enterprises of } \\
\text { the nation's (X5) }\end{array}$ \\
\hline & & $\begin{array}{l}\text { Proportion of export amount in high-tech enterprises } \\
\text { of the nation's (X6) }\end{array}$ \\
\hline & \multirow{2}{*}{ Social benefit } & Growth of Per capita GDP (X7) \\
\hline & & Unit GDP energy consumption (X8) \\
\hline
\end{tabular}

The data of 2012 is selected as the input indicators and that of 2013 as the output indicators, and during the process we refer to the indicator statistics on the website of Science \& Technology Dept. of China. By using SPSS software, the DEA/EFA values of different regions and the scale efficiency can be obtained, as it is shown in Table 2.
TABLE II DEA/EFA VALUES OF DIFFERENT PLACES

\begin{tabular}{|c|c|c|c|}
\hline DMU & C'R & EFA & Scale efficiency \\
\hline Beijing & 1 & 2.335 & unchanged \\
\hline Tianjing & 1 & 0.799 & unchanged \\
\hline Hebai & 0.711 & -0.402 & decline \\
\hline Shanxi & 0.644 & -0.837 & decline \\
\hline Neimenggu & 1 & -0.493 & unchanged \\
\hline Liaoning & 0.529 & 0.105 & decline \\
\hline Jilin & 0.705 & -0.358 & decline \\
\hline Heilongiang & 0.450 & -0.344 & decline \\
\hline Shanghai & 0.632 & 1.695 & decline \\
\hline Jiangsu & 1 & 0.801 & unchanged \\
\hline Zhajiang & 0.756 & 0.978 & decline \\
\hline Anhui & 0.725 & -0.420 & increasing \\
\hline Fujian & 0.535 & 0.132 & increasing \\
\hline Jiangsu & 0.637 & -0.434 & increasing \\
\hline Shandong & 1 & 0.419 & unchanged \\
\hline Hanan & 1 & -0.138 & unchanged \\
\hline Hubei & 0.939 & -0.033 & decline \\
\hline Hunan & 0.701 & -0.194 & increasing \\
\hline Guangdong & 1 & 1.275 & unchanged \\
\hline Guangxi & 0.401 & -0.412 & decline \\
\hline Hainan & 0.666 & -0.467 & increasing \\
\hline Chongaing & 0.628 & -0.305 & increasing \\
\hline Sichan & 0.911 & -0.281 & decline \\
\hline Guizhou & 1 & -1.1901 & unchanged \\
\hline Yunnan & 1 & -0.7341 & unchanged \\
\hline Shanxi & 1 & -0.1481 & unchanged \\
\hline Gansi & 0.575 & -0.735 & decline \\
\hline xinjiang & 0.539 & -0.615 & decline \\
\hline
\end{tabular}

The comprehensive judgment chart can be obtained to evaluate the performance of the financial input to science and technology as seen from Fig. 3.

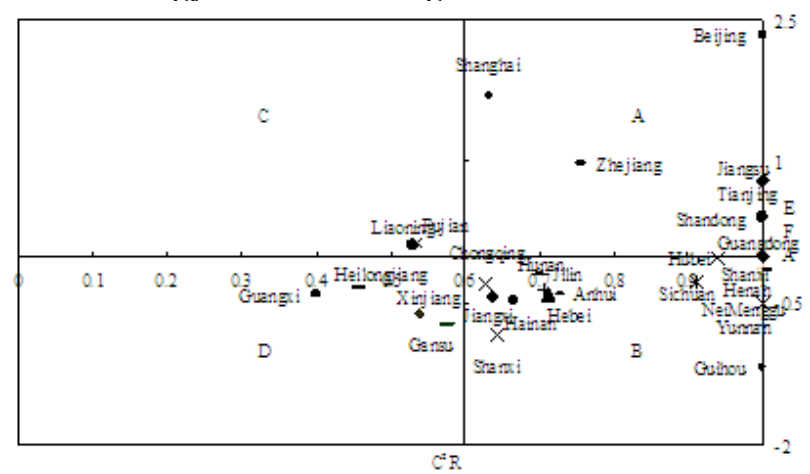

Fig. 3 Chart of the composite performance judgment

Hebei Province falls in the zone with average performance. Compared with the output, the input amount of the finance in science and technology can also be improved while compared with the input, the output of many science and technology indicators is inadequate. Therefore, the performance of the financial input to science and technology is still far from being satisfactory and needs to be improved.

Table 3 shows the evaluation of the overall effectiveness of the financial input to science and technology in Hebei by $\mathrm{C} 2 \mathrm{R}$ model, from which the indicators can be found with inadequate output are transaction value on technology market, proportions of exported high-tech products in the whole country, unit GDP energy consumption. Therefore, these departments 
affecting the science and technology output should be improved. As to its overall effectiveness, specific method for improvement can be worked out by projection and for concrete steps see references.

TABLE III EFfectiveness Evaluation of THE C2R MOdel IN HebeI PROVENCE

\begin{tabular}{|c|c|c|c|c|c|c|}
\hline \multirow{2}{*}{ Provence } & \multirow{2}{*}{\begin{tabular}{|c|}
$\begin{array}{c}\text { Redundant } \\
\text { input }\end{array}$ \\
$\mathrm{S}^{\circ}$ \\
\end{tabular}} & \multicolumn{4}{|c|}{ Inadequate output } & \multirow{2}{*}{\begin{tabular}{|c|}
$\begin{array}{c}\text { effective } \\
\text { values }\end{array}$ \\
$\theta$ \\
\end{tabular}} \\
\hline & & $\mathrm{S}_{1}{ }^{+} \mathrm{S}_{2}{ }^{+}$ & $\mathrm{S}_{3}^{+}$ & $\mathrm{S}_{4}^{+}$ & \begin{tabular}{|l|l|l|}
$\mathrm{S}_{5}^{+}$ & $\mathrm{S}_{6}^{+}$ & $\mathrm{S}_{7}^{+}$ \\
\end{tabular} & \\
\hline Hebei & 0 & \begin{tabular}{l|l}
0 & 0
\end{tabular} & 3.55 & 0.0744 & \begin{tabular}{llll|}
1.956 & 0 & 0.685 \\
\end{tabular} & 0.711 \\
\hline
\end{tabular}

After EFA calculation the component matrix can be obtained, as shown in Table 4. It can be found that the first principal factor occupied a larger loading in per-capita GDP, proportion of finance input to science and technology in public finance expenditure, transaction value on technology market, science and technology papers and unit GDP energy consumption. The contribution rate of variance amounts to $58 \%$, which means the main reason affecting the scientific and technological strength in different regions is the fundamental output of science and technology. The conclusion also conforms to the importance of science and technology to regional development, which means the influence of science and technology is not often for the period, but fundamentally in the long run. For these reasons, to promote the scientific and technological strength in Hebei, it is necessary to improve the output situation of the first principal factor indicators and this is also the key investment direction of the finance input to science and technology from the perspective of investment.

TABLE IV ROTATED COMPONENT MATRIX

\begin{tabular}{|c|c|c|}
\hline & \multicolumn{2}{|c|}{ Component } \\
\cline { 2 - 3 } & 1 & 2 \\
\hline Growth of Per capita GDP & 0.892 & 0.140 \\
\hline $\begin{array}{c}\text { Proportion of finance input to science and } \\
\text { technology in public finance expenditure }\end{array}$ & 0.849 & 0.362 \\
\hline Transaction value on technology market & 0.805 & 0.019 \\
\hline Papers on science and technology & 0.794 & 0.346 \\
\hline Unit GDP energy consumption & -0.659 & -0.189 \\
\hline $\begin{array}{c}\text { Proportion of added value in high-tech } \\
\text { enterprises of the nation's }\end{array}$ & 0.047 & -0.862 \\
\hline $\begin{array}{c}\text { Proportion of export amourt in high-tech } \\
\text { enterprises of the nation's }\end{array}$ & 0.383 & 0.838 \\
\hline $\begin{array}{c}\text { Amourt of patent application and } \\
\text { authorization }\end{array}$ & 0.503 & 0.749 \\
\hline
\end{tabular}

After EFA calculation, the correlation coefficient of the original variable can be obtained, as it is shown in Table 5, from which we can find that the information stands for the degree of correlation between indicators. Take the indicators which have strong radiating effect into key consideration during the finance input decision-making.

TABLE V CORRELATION Matrix

\begin{tabular}{|l|c|c|c|c|c|c|c|c|}
\hline & $\mathrm{X} 1$ & $\mathrm{X} 2$ & $\mathrm{X} 3$ & $\mathrm{X} 4$ & $\mathrm{X} 5$ & $\mathrm{X} 6$ & $\mathrm{X} 7$ & $\mathrm{X} 8$ \\
\hline $\mathrm{X} 1$ & 1.000 & 0.678 & 0.757 & 0.616 & -0.233 & 0.608 & 0.862 & -0.566 \\
\hline $\mathrm{X} 2$ & 0.678 & 1.000 & 0.600 & 0.785 & -0.354 & 0.533 & 0.643 & -0.518 \\
\hline $\mathrm{X} 3$ & 0.757 & 0.600 & 1.000 & 0.268 & -0.461 & 0.818 & 0.567 & -0.485 \\
\hline $\mathrm{X} 4$ & 0.616 & 0.785 & 0.268 & 1.000 & -0.212 & 0.246 & 0.620 & -0.351 \\
\hline $\mathrm{X} 5$ & -0.233 & -0.354 & -0.461 & -0.212 & 1.000 & -0.581 & -0.017 & 0.081 \\
\hline $\mathrm{X} 6$ & 0.608 & 0.533 & 0.818 & 0.246 & -0.581 & 1.000 & 0.531 & -0.412 \\
\hline $\mathrm{X} 7$ & 0.862 & 0.643 & 0.567 & 0.620 & -0.017 & 0.531 & 1.000 & -0.500 \\
\hline $\mathrm{X} 8$ & -0.566 & -0.518 & -0.485 & -0.351 & 0.081 & -0.412 & -0.500 & 1.000 \\
\hline
\end{tabular}

The result of the EFA analysis requires the government to invest more in fundamental output factors of science and technology. It is necessary to strengthen the support to financial invest in science and technology and the increase the proportion of finance input to science and technology in financial expenditures. However, diminishing scale efficiency requires reduce the input scale, which appears to have formed a "paradox" In fact, financial invest in science and technology is closely associated with many indicators as is shown in Table 5. Diminishing scale efficiency means inadequate amount and relative surplus in financial input to science and technology in Hebei. Therefore, when increasing the investment in science and technology, we should optimize the input-output sectors and the factors of science and technology to invest limited resources to the most needed sectors. The result of DEA/EFA requires the government to attach more importance to transaction value on technology market and unit GDP energy consumption. The outputs of the two indicators in DEA analysis are inadequate while in EFA they are important factors to affect fundamental output of science and technology. It can be seen that to improve the performance of the financial input to science and technology in Hebei, it is necessary to optimize resource allocation of science and technology and expand the investment, and measures should be taken to reduce GDP energy consumption and increase transaction value on technology market.

\section{CONCLUSIONS}

Financial input to science and technology is an important method for government to promote the development of science and technology, and its performance evaluation is of advantage for the government to realize and improve their deficiency in order to better promote the overall development of science and technology and economic society. This paper puts forward with new evaluation criterion, constructs performance evaluation model to reduce adverse effect of subjective factors, and overcomes the deficiency of single method, producing more scientific reason analysis and more specific conclusions to improve its performance.

\section{REFERENCES}

[1] Charnes, A., Cooper, W.W. and Rhodes, E., (1978), Measuring efficiency of decision making units,European Journal of Operational Research, 2, pp. 429-444,2002.

[2] Du dong,Wu yan,From "Combination Evaluation" to "One-One Integrating" of Evaluation Method. statistics \& information forum ,23(5)pp. 82,2008.

[3] Wang xue ren,Wang song gui,Applied Multivariate Statistical Analysis,07(22),pp.294-341,1990.

[4] Chen Yan_tai; Chen Guo_hong; LI Mei_juan,Classification \& research advancement of comprehensive evaluation methods. Journal of Management Sciences in China, 7(2),pp.70,2004.

[5] Niu Chong huai, Tang Chao yong, Jiang Hai yang, On the Co integration and Causality between Fiscal Expenditure for Science \& Technology and Economic Growth. Social Sciences Journal of Colleges of Shanxi. 20(2),pp.55-57,2008. 